\title{
A numerical investigation into effect of airfoil on aerodynamic characteristics for SB-VAWT
}

\author{
Jian Yong Zhu ${ }^{1,2, a}$, Pei Qing Liu ${ }^{1}$ \\ ${ }^{1}$ Key Laboratory of Fluid Mechanics of Ministry of Education, Beihang University, Beijing , China \\ ${ }^{2}$ Faculty of Aerospace Engineering, Shenyang Aerospace University,Shenyang, China \\ amichellend@126.com
}

\begin{abstract}
Keywords: wind energy; SB-VAWT; airfoil; aerodynamic characteristics; numerical simulation Abstract. The straight-bladed Darrieus type vertical axis wind turbine (SB-VAWT) has received considerable attention due to relatively high efficency of wind energy and simple blade design. Slection of airfoil is crucial for aerodynamic characateristics of SB-VAWT. A numerical investigation into performance of SB-VAWTs is carried out with several symmetric airfoils as well as asymmetric airfoils. The simulation method is through solving unsteady compressible RANS equations and $S S T-k w$ turbulence model. The numerical results indicate, the thinner airfoil contributes to higher power coefficient peak, but leads to poorer self-startup performance. The asymmetric airfoil has advantages over symmetric one in improving aerodynamic performance. The different setup configurations of asymmetric airfoil NACA 4415 is also considered, which shows the concave-in configuration is more beneficial to improve power coefficient peak.
\end{abstract}

\section{Introduction}

It is a well-known fact that wind energy is quite important as one of clean energy resources. Utilization of wind energy is an effective way to solve energy and environment issues[1][2]. Wind turbines convert wind energy into mechanical energy, however wind turbines with different types present various power efficiency. SB-VAWT is a typically vertical axis wind turbine, relying on aerodynamic lift for work. SB-VAWT is attractive for its relatively high power efficiency and simple blade design[3].

Selection of airfoil is very important for aerodynamic performance of the wind turbines, the lift-drag performance of airfoil is directly related to wind energy conversation efficiency of the wind turbines. Islam [4] discussed the aerodynamic characteristics of a desirable airfoil for a self-starting and better performing SB-VAWT. Howell[5] conducted a combined computational and experimental study on the performance of a small VAWT. Bhutta[6] provided a review of various configurations and design techniques of VAWT. Zhu[7] theoretically and experimentally analyzed the static torque characteristics for H- Darrieus wind turbines. Wang[8] provided flow control technology to improve the aerodynamic performance of $\mathrm{H}$-type wind turbine. Hill[9] used a numerical model to simulate the starting of an H-rotor Darrieus turbines under steady wind conditions.

In this paper, several symmetric and asymmetric airfoils are selected and numerically simulated. The effect of airfoil on aerodynamic performance of VAWT is analyzed.

\section{Research programs}

\section{Calculation model and mesh}

In order to improve calculative efficiency, a two-dimension model of VAWT is used, composed of three blades, with the blade chord lengh $c$ of $1.2 \mathrm{~m}$ and the rotation radius $R$ of $15 \mathrm{~m}$. The pitch angle of the blade is $0^{\circ}$. The dimensions of the rotor and the computational domain are shown in Fig 1 . The computational domain is the circular region with the radius of $30 R$. The boundary condition at upstream semicircle is set as velocity inlet with $9 \mathrm{~m} / \mathrm{s}$, and the boundary condition at downstream semicircle is set as pressure outlet with the static pressure of $0 P a$. The computational domain is divided into two areas and the rotor is included in the rotational zone. Figure 2 shows the mesh distribution near the blade, the structured meshes is generated in both zones and the mesh amount 
exceeds $10^{5}$. The sliding mesh technique is used to treat with the relative movement between the rotational zone and stationary zone.

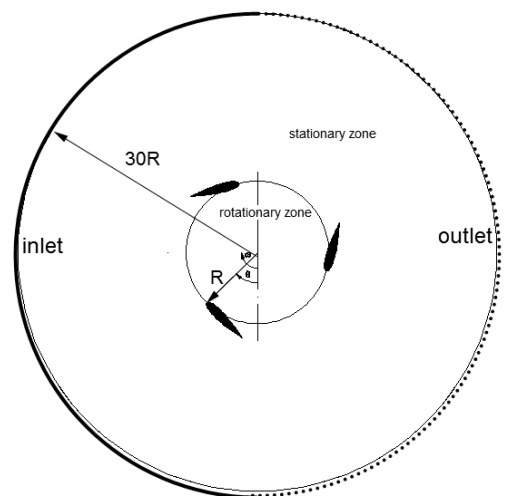

Fig. 1 The dimension of the 2D VAWT

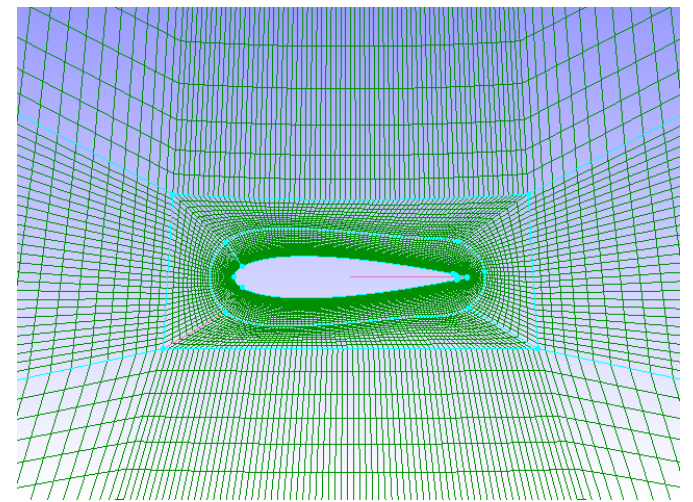

Fig.2 The mesh distribution near the blade

\section{Calculation method and calculation condition}

The unsteady compressible RANS equations and the $S S T-k w$ turbulence model are solved by the Fluent software. The wind flows horizontally form left to right. The rotor rotates counter-clockwise and the position of the rotor in Fig. 1 represents the initial azimuth $\theta$.

The selected airfoils include NACA0012, NACA0015, NACA0021, NACA4415 and NACA4418. The calculation conditions include the static torque values at different azimuths and the output power at different rotation velocities for the rotor with different airfoils. The static toque values represent the startup performance and the output power represents the overall aerodynamic performance of the rotor. In generally, the output power and rotation velocity are in dimensionless treatment to get power coefficient $C p$ and tip speed ratio $\lambda$. The output power, power coefficient $C p$ and tip speed ratio $\lambda$ are separately calculated through the Eq. (1) Eq. (3).

$$
\begin{aligned}
& P=2 M \pi n / 60 \\
& C_{P}=P /\left(2 \rho V^{3} S\right) \\
& \lambda=n \pi R /(30 V)
\end{aligned}
$$

Where $\rho$ means the air density, $M$ means the moment of torque, $\mathrm{n}$ means the rotation velocity, $S$ means the rotor swept area.

\section{Analysis and discussion}

\section{Static toque values}

The phase averaged static torque is obtained by averaging the static torque values in one period of rotation. What is more, as to the asymmetric airfoil, there are two setup configurations based on the concave curvature of the camber line, including concave-out and concave-in as shown in Fig3.

Figure 4 shows the phase averaged static toque values of the rotor with different airfoils. As to the symmetric airfoils (namely NACA0012, NACA0015 and NACA0021), $T_{S}$ increases with the increase of airfoil thickness, indicating relatively thick airfoil contributes to improve self-startup performance. For the asymmetric airfoils (namely NACA4415 and NACA4418) with the concave-out configuration, $T_{S}$ is clearly higher than those of symmetric airfoils, beside, the relative thicker NACA4418 is also superior to NACA4415. However, NACA4418 with the concave-in configuration shows considerably low $T_{S}$, relatively to the same airfoil with the concave-out configuration. 

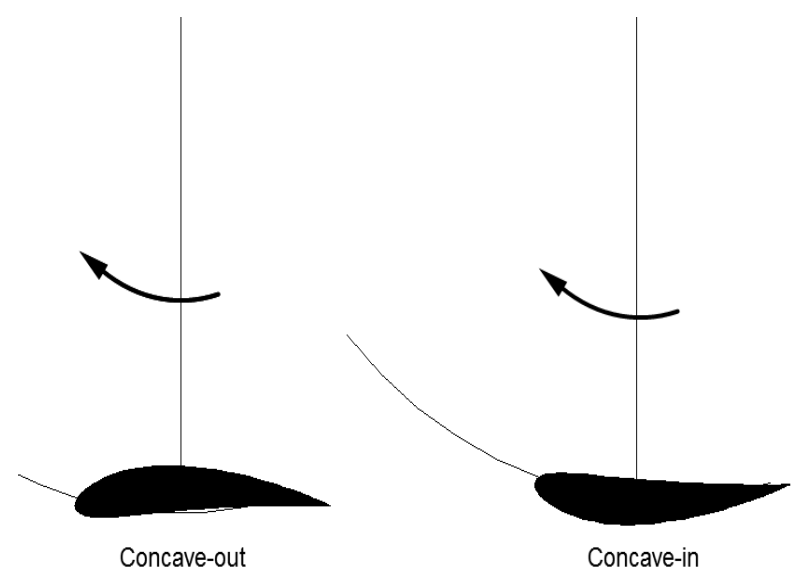

Fig.3 Two types of setup configurations

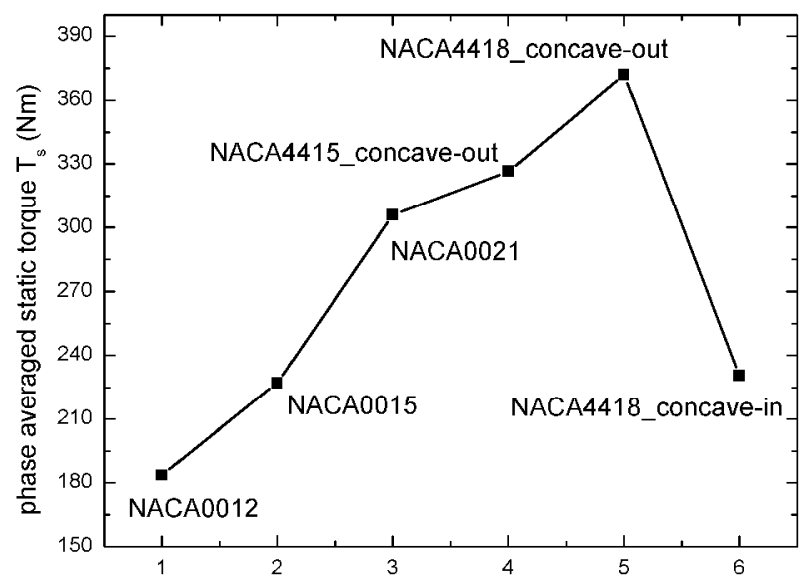

Fig.4 The phase averaged static torque

\section{Power output}

(1) Fig 5 shows the relationship between power coefficient $C p$ and tip speed ratio $\lambda$ for symmetric airfoils, the $C p$ first increases, then decreases, with the increase of $\lambda$. The maximum $C p$ and corresponding $\lambda$ increase with the decrease of airfoil thickness, though the thinner airfoils are inferior during the relatively low $\lambda$. The results also show that the symmetric airfoil exhibits excellent performance, for example, the maximum $C p$ of NACA0012 can reach 0.403 at $\lambda=4$.
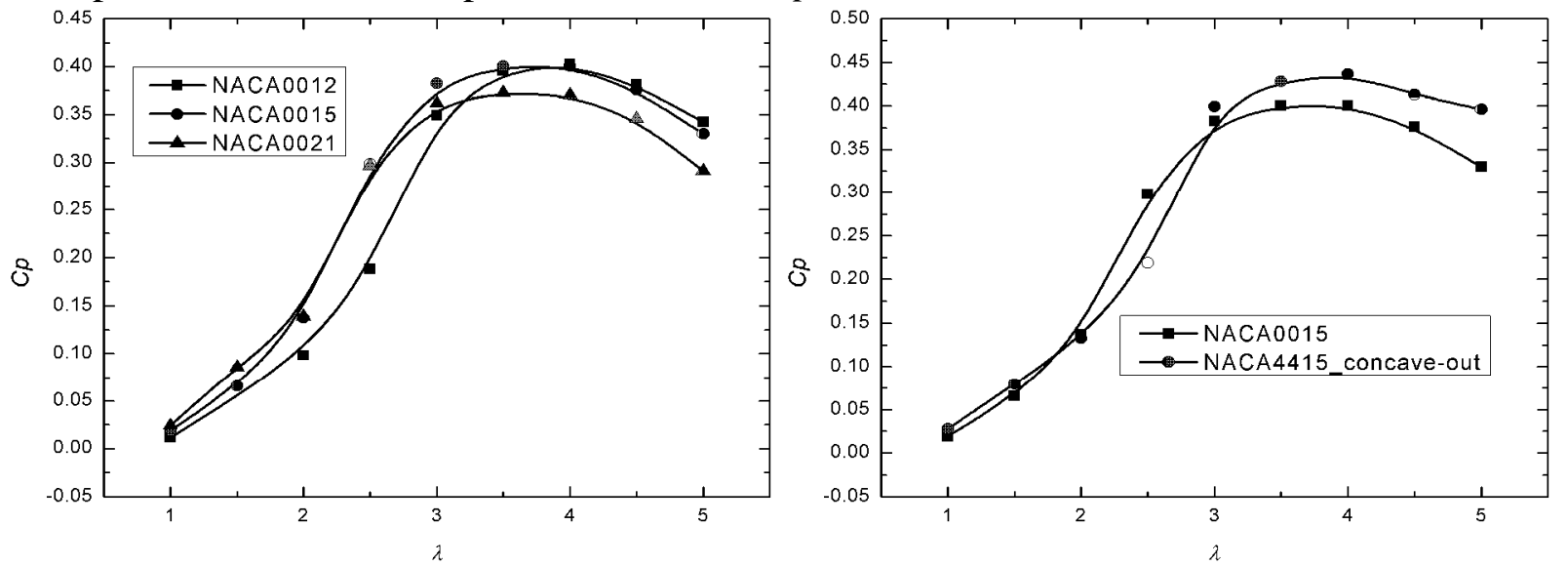

Fig.5 $C_{p} \sim \lambda$ curves of symmetric airfoils Fig.6 $C_{p} \sim \lambda$ curves between NACA0015 and NACA4415

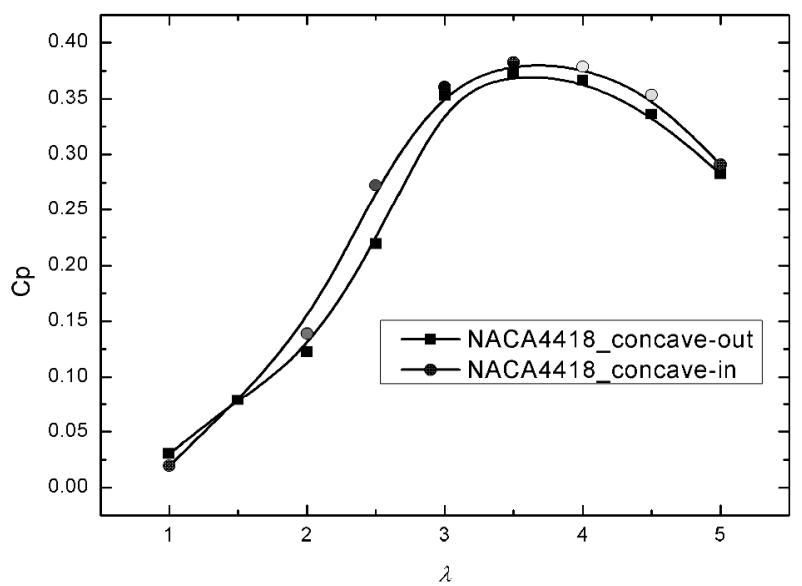

Fig.7 $C_{p} \sim \lambda$ curves of two setup configurations

(2) Fig 6 shows the effect of airfoil camber on the aerodynamic performance of the rotor. NACA0015 and NACA4415 have the same thick, however, NACA4415 has the relative camber of $4 \%$ at $40 \%$ of the chord. As shown in Fig 6, NACA4415 with concave-out configuration is superior to NACA0015 in output power during nearly all range of $\lambda$. 
(3) Fig 7 shows the effect of airfoil setup configuration (namely NACA4418_concave-out and NACA4418_concave-in) on the aerodynamic performance of the rotor. It is found that, except for the $\lambda$ less than 1.5, the $C p$ of concave-in configuration is obviously better than that of concave-out configuration, indicating the concave-in configuration of asymmetric airfoil has potential in improving maximum $C p$.

\section{Conclusions}

In this paper, the effect of airfoil on the aerodynamic performance of SB-VAWT is numerically investigated, at the same time, considering the effect of airfoil thickness, camber and setup configurations. Based on the numerical results, we come to the following conclusion.

1) The conventional NACA series of airfoils exhibit relatively excellent aerodynamic performance for the SB-VAWT with low solidity. Careful selection of airfoil contributes to improving performance of the rotor.

2) The relatively thicker airfoil presents higher static toque value, contributing to self-startup performance, while inferior in reading maximum power coefficient.

3) The asymmetric airfoil has advantage to symmetric one in performance of the rotor. It is noted that setup configuration has great influence. The asymmetric airfoil with concave-out configuration prevails over symmetric airfoil in self-startup performance and output power. Whereas the asymmetric airfoil with concave-out configuration has poor self-startup performance, exhibiting the optimum output power performance.

\section{References}

[1] Zhu Jianyong, Liu Peiqing, Qu Qiulin, et al. Experimental investigation on aerodynamic performance of helix Savonius rotor. Journal of Basic Science and Engineering, Vol.23-5 (2015) , p.1059-1067

[2] S. Eriksson, H. Bernhoff, and M. Leijon. Evaluation of different turbine concepts for wind power. Renewable and Sustainable Energy Reviews, Vol.12-5 (2008), p.1419-1434

[3] D. Saeidi, A. Sedaghat, P. Alamdari, and A. A. Alemrajabi. Aerodynamic design and economical evaluation of site specific small vertical axis wind turbines. Applied Energy, Vol.101 (2013), p.765-775

[4] M. Islam, D. S.-K. Ting, and A. Fartaj. Desirable airfoil features for smaller-capacity straight-bladed VAWT. Wind Engineering, 31-3 (2007), p 165-196

[5] R. Howell, N. Qin, J. Edwards, and N. Durrani. Wind tunnel and numerical study of a small vertical axis wind turbine. Renewable Energy, 35-2 (2010), p 412-422

[6] M. M. Aslam Bhutta, N. Hayat, A. U. Farooq, Z. Ali, S. R. Jamil, and Z. Hussain. Vertical axis wind turbine - A review of various configurations and design techniques. Renewable and Sustainable Energy Reviews, 16-4 (2012), p 1926-1939

[7] Zhu Jianyong, Wang Jianming, Liu Peiqing. Theoretical Analysis and Experimental Investigation of Static Torque Characteristic for H-Darrieus Wind Turbine.Journal of mechanical engineering, 53-2 (2017), p.150-156

[8] Wang Jianming, Chen Chao, Zhu Jianyong. Experimental invetigation of the flow control applied for H-Type wind rotor. Power system and clean energy, 30-10 (2014), p 119-123

[9] N. Hill, R. Dominy, G. Ingram, and J. Dominy.Darrieus turbines: the physics of self-starting. Proceedings of the Institution of Mechanical Engineers, Part A: Journal of Power and Energy, 223-1 (2009), p. 21-29 